\title{
Geography versus institutions and sub-Saharan aid
}

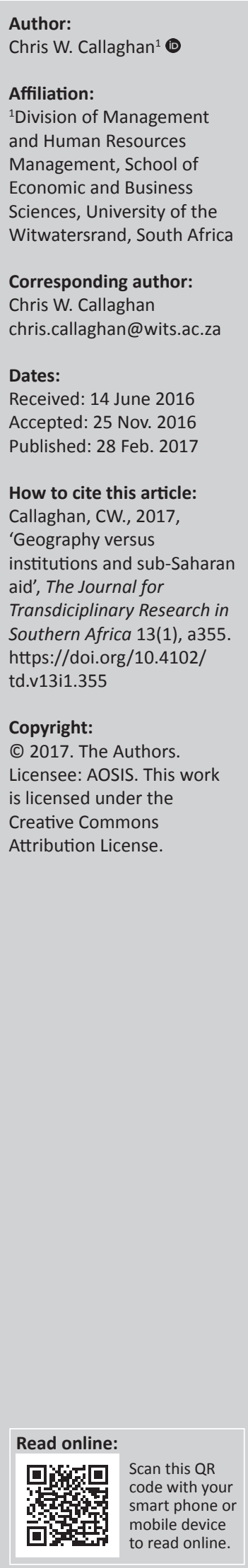

This article sets out to review two opposing viewpoints in the literature, namely long-standing geographic versus institutionalist perspectives and their opposing predictions for development of poor countries, particularly those in sub-Saharan Africa. A special focus is on the differing predictions of the effectiveness of aid of these two perspectives. On the basis of a consideration of different literatures and final Millenium Development Report, it is argued that 'Big Push' theory may still offer important theoretical and practical development contributions. Arguably, these contributions echo Keynes's legacy in their consideration of the most vulnerable and marginalised. It is also argued that a global birth lottery allocates people to countries and regions with unequal opportunities and that a normative argument can be made to justify aid to mitigate birth lottery effects.

\section{Introduction}

Income and growth divergence between rich and poor countries is an important issue in development literature. Average income levels in the world's richest and poorest nations 'differ by a factor of more than 100'; Sierra Leone's per capita GDP of $\$ 490$ contrasts starkly with Luxembourg's \$50 061 shortly after the millennium (Rodrik, Subramanian \& Trebbi 2004:132). Middle-income traps (Luiz 2016) and low-income traps (Sachs et al. 2004) persist in African economies, contesting certain predictions of growth theory. Although growth theory offers 'proximal' theory premised on physical and human capital accumulation, and endogenous growth theory explores the role of technological change, three deeper determinants of economic growth are considered to have a dominant influence on development, namely geography, trade and institutions (governance) (Rodrik et al. 2004).

However, relative importance of these deep determinant factors for sub-Saharan country development has been contested (Rodrik et al. 2004; Sachs et al. 2004), particularly relative contributions of geography versus institutions. Knowledge of these relative contributions is especially important as they have different implications for development interventions, particularly for aid-based intervention. This tension is the knowledge problem this article seeks to address.

This article, therefore, attempts to make a contribution to this debate in three ways. Firstly, literature which advocates a big push approach to aid is considered. This perspective is shown to be related to the geographic-centric view that fundamental constraints to development can ensnare poor countries in a poverty trap, in which preconditions to growth cannot become established. An argument is offered that 'geographic inequity' may differentiate an individual's life chances on the basis of a global geographical 'birth lottery'. Consequently, only an interventionist perspective (such as on the scale of Keynes's vision) may capture the vision required to rally people and resources around large-scale objectives associated with 'big push' logics. This 'arbitrary' allocation of individuals to different geographic regions or countries through birth is defined here as the birth lottery effect. It is argued that the analysis and work of Sachs et al. (2004) offers a vision which, albeit normative, continues to be useful in contemporary African development, and which has perhaps been borne out by millennium goal achievements to date.

Secondly, literature arguing for the dominance of institutions versus geography in this debate is considered. Econometric evidence offered by Rodrik et al. (2004) and Easterley (2006) is discussed together with arguments questioning the effectiveness of large aid-based interventions as well as the millennium development goals (MDG) process and its linkages with the big push agenda. This literature is juxtaposed with a discussion of geography and literature highlighting the importance of transport costs as a constraint to development and the way geography might rule out certain paths to development, such as assembly manufacturing. Certain models are then considered, one of which predicts contemporary divergence on account of historical differences in transport costs and an argument is considered which presents geography as a causal force which 
can shape tax choices and governance quality. It is argued that evidence does not discount geographical inequity as a structural constraint to development, supporting Sachs et al. (2004) arguments in favour of aid interventions, particularly on a scale sufficient to counteract geographical inequity and thereby to provide preconditions for development.

Thirdly, literature relating to aid flows is considered, in relation to the big push arguments. Sachs et al. (2004) have advocated dramatically increased levels of aid. Their logic is that a 'big push' approach might dislodge impoverished economies from poverty traps or set these economies on sustainable developmental paths. Much of the literature concerns a critique of the MDG process which in some instances is inextricably linked to the big push arguments. The MDG process culminated in 2015, its target date. An overview of the successes of the MDG process, concluded in 2015, is then provided. In the light of substantive inroads made on account of very large increases in aid, as reported in the MDG report, it is argued that the work of Sachs et al. (2004) offers a theoretical, as well as practical contribution, to the lives of those under conditions of extreme poverty and deprivation. These issues are considered especially important for Southern African countries. These countries face the world's highest disease burden associated with HIV, on top of other challenges shared with other sub-Saharan countries. Given constructive critiques of aid initiatives (Anderson, Brown \& Jean 2012), with reference to the literature, this article also seeks to offer specific examples of areas in which aid might be effectively used to enable growth. This article therefore seeks to build on previous research related to the Southern African context and development aid assistance (see e.g. Bezuidenhout 2009; De Wall \& Whiteside 2003; Fowler 1991; Zerbe 2004) in order to give consideration to arguments that support increasing aid to vulnerable populations.

The article proceeds according to the sequence described above. Big push theory is now introduced and discussed as follows.

\section{Aid in the context of the geography- institutions debate: Big push theory}

There is a general agreement that sub-Saharan African countries face an extraordinary crisis. Sachs et al. (2004) argued that sub-Saharan Africa (termed 'Africa' hereforth) faces a unique development crisis. This crisis is reflected in negative income per capita growth across the years 1980-2000 while at the same time having to deal with health challenges such as AIDS and resurgent malaria compounded by rising antimalarial drug resistance and ineffective health systems.

Sachs et al. (2004) offered an analysis of 23 sub-Saharan African countries. These countries together in 2001 had a population of 617 million with a population-weighted average income of $\$ 271$ per person (74 cents per day). Further, these countries had an average life expectancy at birth lower than 60 and child mortality rates of more than 100 deaths before 5 years of age per 1000 live births.
On the basis of their analysis, Sachs et al. (2004:121) contested the 'standard diagnosis' that 'bad government' or weak institutions are the primary cause of sub-Saharan developmental challenges. Instead, they argued that African country governance is not on average worse than elsewhere when income levels are controlled. This argument stands in contrast to others who have stressed the primary role of institutions as the fundamental determinant of development (Acemoglu, Gallego \& Robinson 2014; Acemoglu, Johnson \& Robinson 2001; Rodrik et al. 2004).

Furthermore, according to Sachs et al. (2004:121), crosscountry regressions controlling for initial income and quality of governance using different measures show sub-Saharan African countries to grow more slowly than other developing countries (with an annual point difference). Consequently, they argued that Africa's crisis requires a better explanation than governance alone.

Other explanations of differences between developed and developing country growth have been the subject of longstanding debates. These debates have largely pitted neoclassical school growth models building on Solow's (1956) seminal tradition (which some have come to term exogenous growth models according to Parente 2001) against other schools of thought, such as those associated with endogenous growth theory (Romer 1994). Although the former largely focus on the different effects of capital, labour and technological change, the latter focus on investments in human capital, innovation and knowledge. What differentiates Sachs et al.'s (2004) work from these is essentially the argument that many African economies are stuck in 'poverty traps' and are thus unable to take advantage of opportunities for growth suggested by exogenous or endogenous growth theories.

On the basis of their findings, Sachs et al. (2004) argued that tropical Africa, including its well-governed economies, are stuck in a poverty trap and are therefore simply too poor to grow. This poverty trap mechanism works through the effect of extreme poverty levels which result in low national savings rates. These low national savings rates are not offset by private foreign capital inflows nor by foreign direct investment because poor infrastructure and human capital endowments disincentivise these flows.

Extremely low domestic savings and low market-based foreign capital inflows, therefore, make it difficult for Africa to escape this poverty trap. A 'big push' is therefore needed to provide a fast 'step' increase in underlying rural and urban productivity, and foreign donor intervention is therefore key to this, according to Sachs et al. (2004). At the heart of the rationale behind big push aid interventions, however, is the poverty trap conception.

The notion of poverty traps is not new. Sachs et al. (2004) acknowledged the poverty trap for underdeveloped countries first formally modelled by Nelson (1956:894), who offered the following synopsis of the original concept:

The malady of many underdeveloped economies can be diagnosed as a stable equilibrium level of per capita income at or 
close to subsistence requirements. Only a small percentage, if any, of the economy's income is directed toward net investment. If the capital stock is accumulating, population is rising at a rate equally fast; thus the amount of capital equipment per worker is not increasing. If economic growth is defined as rising per capital income, these economies are not growing. They are caught in a low-level equilibrium trap.

Sachs et al. (2004) developed on this to offer a theory of Africa's poverty trap using a standard neoclassical growth model. In this model, output per capital $(q)$ is produced. The model also includes a production function $(A f(k))$, with $A$, the total factor productivity, and $k$, the capital-labour ratio. Further, $s$ represents the national savings rate, $d$ is the rate of capital depreciation and $n$ is the rate of population growth. The rate of capital accumulation is therefore:

$d k / d t=s A f(\mathrm{k})-(n+d) k$

[Eqn 1]

Change in the capital-labour ratio itself reflects capital deepening, and $(n+d) k$ represents capital widening, or the amount of per capita savings needed to maintain the capitallabour ratio against rises in population and depreciation. This equation therefore posits capital deepening as a function of savings per capital less capital widening. In this model, per capital growth can only occur if saving per capital is greater than capital widening. Therefore, if savings is less than capital widening, a decline in output per capita results.

However, according to Sachs et al. (2004), a shortcoming of this neoclassical model is its assumption that the economy will necessarily grow with very low levels of $k$. The assumption is that $s A f(k)$ is very steep at the origin and steeper than $(n+d) k$ at the origin. Furthermore, it is also assumed that $d k / d t$ is equal to vertical difference between $s A f(k)$ and $(n+d) k$ such that from a low capital-labour ratio, $k$ and $q$ rise asymptotically to a steady-state equilibrium. This is, however, a special case, as when $k$ is extremely low, marginal productivity of capital is also low (not almost infinite, as in the classic model), as a minimum level, or threshold of capital is a necessary condition before modern production processes can begin. This is clear from the example of factory production, which requires basic infrastructure in the form of electricity, ports, as well as literate and numerate human capital endowments.

Without these infrastructure endowments, small increments of $k$ may have very little influence. However, once these basic endowments are present, it is then entirely possible that marginal productivity of capital can rise steeply. A further effect is present when $k$ is very low, as saving rates can be low or negative, and current income is all used to maintain basic needs, and a savings trap can result (Sachs et al. 2004). Under savings trap conditions, $s A f(k)$ can be less steep than $(n+d) k$ at very low levels of $k$, but can become more steep at intermediate range. The implication of this is that in economies starting with extremely low capital, the capital-labour ratio and output per capital can tend to decline over time, as the poor get poorer absent of capital accumulation in the face of increasing population. Hence, only (somehow) by raising the capital-labour ratio above a minimum threshold can economic growth be achieved and steady-state convergence be obtained.

The argument that extremely impoverished countries cannot develop without the necessary infrastructure seems incontestable. Deriving from Sachs et al.'s (2004) analysis, it is argued in this article that aid to countries might be justified on normative grounds and that perhaps aid should reach those impoverished in the same way it would reach them if the global lottery of birth had placed them within the borders of a rich country. It is acknowledged that this perspective is purely normative, but is taken to perhaps be a logical extension of Sachs et al.'s (2004) big push approach. This criteria, of equity in geographical allocation, is therefore a measure of unfairness in global resource allocation.

Empirical evidence in the literature suggests that savings rates are typically extremely low at low-income levels but can rise as levels of income increase. Yet, a poverty trap can also be caused by very rapid population growth at low levels of $k$ (Sachs et al. 2004). Poverty traps are therefore multidimensional and can include interactive effects which maintain a vicious circle of underdevelopment. It is argued here that these are systemic interactive effects which require an extraordinary intervention on a large enough scale to break through such constraints to development.

Capital thresholds, saving traps and demographic traps all interact, and although each can cause a trap, their combined influence can be debilitating. Sub-Saharan Africa, and by extension, Southern Africa, is disproportionally exposed because of (1) high transport costs and small market size, (2) low agricultural productivity, (3) high disease burdens, (4) geopolitical challenges and (5) very low levels of technology diffusion from global sources (Sachs et al. 2004). These conditions place geography at the heart of the problem of relative inequality and poverty of these economies. Arguably, the importance of this argument is clear, and beyond methodological question in terms of empirical analysis because as an exogenous structural constraint to development, no amount of instrumentation in relative weights of regression analyses can contest its primary direct influence on other determinants of development. The logic Sachs et al. (2004) espoused here suggests that aid could and should be used to balance the geographical constraints to development. These geographical constraints are considered substantively unfair, providing a normative rationale for intervention through aid inflows and inflows on the scale required to achieve geographical equity and thereby generate preconditions for development.

Despite a crisis in legitimacy in the 1990s, since 2000, United Nations and World Bank calls for doubling of aid to meet international development targets have resulted in increased aid flows to developing countries (Loots 2006). Net official development assistance (ODA) flows to African countries have risen from a 1970 s average of $\$ 4.9$ billion to $\$ 12.45$ billion in the 1980s, and then to a high of $\$ 25.2$ billion for 1990 . 
Flows then decreased to $\$ 21.1$ billion by 2002 , comprising the largest capital flows to the continent, exceeding foreign direct investment as well as worker remittances (Loots 2006). In calls for drastic increases in aid, Sachs et al. (2004) followed a long-standing tradition of calls for dramatic increases in aid (see Rosenstein-Rodan 1961).

The distribution of aid itself has perhaps not been independent of geography. Africa has not had the geopolitical strategic status of other global regions which have received global aid (Sachs et al. 2005), compounding this disadvantage. Sachs et al. (2004:139) stressed that they 'are not arguing for any geographic determinism' and that their 'whole point' is the opposite:

Africa's structural impediments can be overcome if they are compensated by an intensive investment program that directly confronts the continent's high transport costs, low agricultural productivity, heavy disease burden, colonial legacy of poor educational attainment, and the like. We are arguing, however, that Africa's structural problems help to account for its current trap.... Poor governance no doubt complicated the task - many natural resource rents were squandered - but the poor governance itself was as much symptom as cause. To break out of the poverty trap, Africa needs help, and it has not yet gotten it in the form and to the extent that is necessary.

In order to critically develop the central argument of this article that Sachs et al. (2004) essentially provide a useful rationale for increasing the scope of aid (based on the geography equity notion) and that aid should be increased to mitigate the global birth lottery effect, it is first necessary to consider other perspectives and empirical analyses which contest the centrality of geography as the basis for aid provision. Certain of these perspectives are now considered in the following sections.

\section{Dominance of institutions in econometric analysis}

Rodrik et al. (2004) acknowledged three 'deep determinant' theoretical arguments relating to global inequality development, which, importantly, have different implications for efforts to address it. According to these arguments, (1) geography is central to poverty and inequality of economies, (2) international trade (trade fundamentalist stance) is the primary cause of productivity change, a perspective termed the integration view (with market integration at the heart of potential convergence) and (3) institutions, and more specifically the maintenance of property rights and rule of law (institutionalist stance), are the most pervasive influence on growth. Although growth theory offers 'proximal' theory premised on physical and human capital accumulation, and endogenous growth theory explores the role of technological change, the three dominant deeper determinants of economic growth are really 'the factors that determine which societies will innovate and accumulate, and therefore develop, and which will not' according to Rodrik et al. (2004).

Figure 1 reflects Rodrik et al.'s (2004) process of testing the relative contribution of geography, integration and

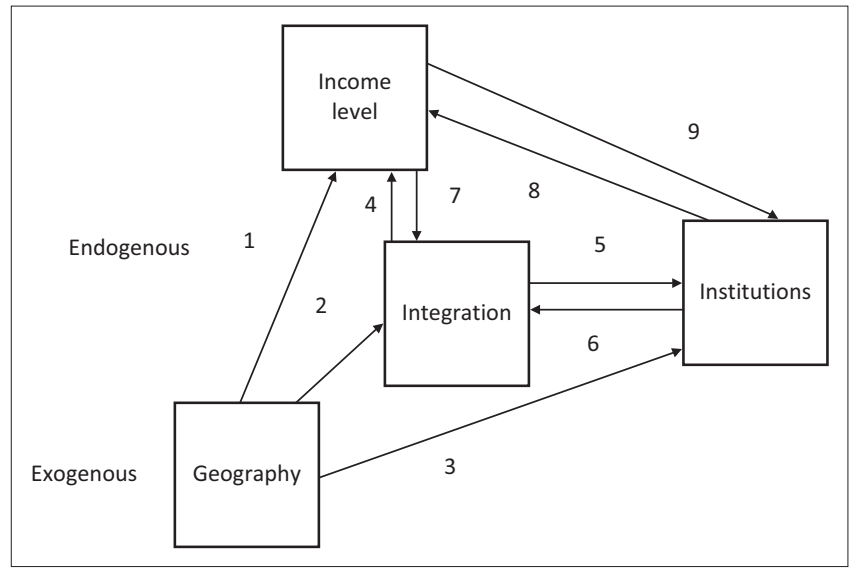

Source: Rodrik et al. (2004:134)

FIGURE 1: Potential relationships between the deep determinants of income.

institutions to income. They used instrumental variable regressions to test these relationships. Geography may have a direct effect on incomes through agricultural productivity and morbidity (modelled as arrows (arrow 1) in Figure 1). It might also have an indirect effect through distance from markets and integration (arrow 2) or impact on institutions (arrow 3), which can include the deleterious influence of resource endowments on incomes, the 'resource curse'. However, the influence of geography is exogenous to the direct and indirect influences of integration, or trade effects, and institutions, the latter two contributing endogenous effects (Rodrik et al. 2004). The centrality of geographic constraints to development (Sachs et al. 2004) is clear from this analysis as the geographic effect is theoretically common to all three other components of the model.

Trade fundamentalists argue for the primacy of effect (arrow 4), or the direct effect of integration on incomes and (arrow 5) the direct effect on institutions which then transmits, via an indirect effect, to income level via this direct effect on institutions. In addition, they argue that reverse causality effects (arrow 6) and (arrow 7) are relatively non-significant. On the contrary, institutionalists typically argue for the primacy of effect (arrow 8) and that institutional quality is not simply the result of higher incomes themselves (arrow 9) or simply integration (arrow 5) (Rodrik et al. 2004). In order to test these effects econometrically, Rodrik et al. (2004) use trade or GDP shares derived from a gravity equation for bivariate trade flows as an instrument for actual trade or GDP ratios, and settler mortality rates as an instrument for institutional quality. They apply the instruments simultaneously to test the three categories of deep determinants of incomes and their independent contributions to cross-national variation in income levels (the relationships shown in Figure 1). Rodrik et al. (2004) therefore tested the following equation, with $y_{i^{\prime}}$ the income per capita of country $i ; I N S_{i^{\prime}}$ the measure for institutions; $I N T_{i^{\prime}}$ the measure of integration; $G E O_{i^{\prime}}$ the measure of geography; and $\varepsilon_{i}$ the random error term.

$\log y_{i}=\mu+\alpha I N S_{i}+\beta I N T_{i}+\gamma G E O_{i}+\varepsilon_{i}$

[Eqn 2]

Interestingly, in the first-stage analysis, the constructed openness measure is found to predict institutions as well 
as integration, which does not seem to rule out the potential influence of trade on institutions. Rodrik et al. (2004:151) concluded overall that 'there seems to be some albeit modest, support for the direct impact of geography on income, although one that is not as robust as that of institutional quality'.

Overall, Rodrik et al. (2004) found quality of institutions to be the dominant relationship with income levels; with institutions controlled for, geographic effects are found to have weak direct effects and strong indirect effects through their influence on institutions, and with institutions controlled, trade is not significant. These findings echo other research arguing for the importance of institutions (e.g. Acemoglu et al. 2001, 2014).

However, it is argued here that the centrality of institutions is an argument 'downstream' of the separate argument that aid needs to equalise disadvantages associated with geographical constraints to development. This is not to diminish the importance of institutions. There are certain aspects, however, of Sachs et al.'s (2005) analysis which are also contested by Easterley (2006), who offers a more detailed critique of the big push literature in general. This critique is now considered.

\section{Theoretical and empirical challenges to the big push agenda}

Contesting Sachs et al.'s (2005) analysis of the causes of poverty traps, Easterley (2006) stressed that poverty traps may fundamentally be caused by bad policies and institutions. He argued that the 'classic aid narrative [has] paid little attention to this possibility' and that the 'revival of the narrative today also downplays the bad government explanation for poverty' (Easterley 2006:294). If poor government was the only cause of poor performance, and if it was independent of other influences such as geography, then aid would not only be ineffective but it would also not address the primary cause of poverty and underdevelopment. However, these two 'ifs' seem to be based on assumptions which are not uncontested, as discussed in preceding sections.

Easterley questioned a host of big push assumptions, taking issue with the Millennium Projects stance that even wellgoverned countries are simply too impoverished to grow as well as aid-centred approaches to development in general for failure to consider aid effectiveness in the light of potential effects of aid on fertility. Easterley (2006:294) stressed that 'aid that raises personal income may increase population growth by more than the necessary increase in saving, theoretically perpetuating the poverty trap'. He also argued that little empirical evidence supports the notion of high returns to human and physical capital from alreadyimplemented big pushes. According to data for the period 1970-1994 for 22 African countries, big push public investments have not produced a rapid step increase in Africa's underlying rural or urban productivity as over this period. These countries were found to have spent $\$ 342$ on public investment and donors $\$ 187$ in aid, with a step increase in productivity (measured as per capital growth) of zero.
Using data on per capita income from 1950 to 2001 for 137 countries, Easterley (2006) tested two criteria, namely whether poorest countries have significantly lower per capital growth and whether their growth is zero. He argued that if the first criterion holds but not the second, then a relative poverty trap exists. However, his findings suggested that the poorest fifth of countries in 1950 increased income over the following 50 years 2.25 times, and the others by 2.47 times, with no statistically significant difference in growth rates between these two groups. Such tests, however, do not seem to take into account the fact that for poor countries this growth is off an extremely small base.

Central to the debate around the importance of institutions, Easterley (2006) found that measures of government quality strongly predict growth across 1960-2002, with initial income negative. Easterley (2006:307) therefore concluded that 'recent stagnation of the poorest countries appears to have more to do with bad government than with a poverty trap, contrary to the "well-governed poverty trap" hypothesis'.

However, Easterley (2006:307) subsequently acknowledged that his conclusion 'does not necessarily support an exclusive focus on good government as the key to growth and development'. This is taken to be an important acknowledgement, because it 'opens the door' to notions that aid intervention can play an important role in growth and that the story is not only about institutions, as Rodrik et al. (2004) have tried to suggest. Having considered arguments contesting the big push advocacy literature, literature supporting big push arguments is now considered.

\section{Literature in support of big push interventions: Roots}

The big push literature builds off a long tradition of work which has sought to justify interventions in support of poorer regions or economies. According to Rosenstein-Rodan (1943:203), the principle of international division of labour requires labour to move towards capital (emigration) or capital towards labour (industrialisation). In this way, a waste of labour is avoided, a process suited to an interventionist development path preferable to the autarkic route of nonintervention (Rosenstein-Rodan 1943).

The take-off literature can be traced back to work by Rostow (1960). Rostow (1960) identified a state of societal development which achieves preconditions for take-off. On reaching this state, a country is able to capture benefits of modern scientific methods and overcome diminishing returns through attainment of new production functions in both agriculture and industry. The state also gains the social and political structures to support this (typically reached through interventions by other societies). What is clear from Rostow's (1960) analysis is the argument for strong intervention to ensure take-off occurs. 
For Sachs (2005:3), aid is central to escaping the poverty trap, a vision he shares with that of another, of a different time (of Keynes):

Eighty-five years ago the great British economist John Maynard Keynes pondered the dire circumstances of the great depression. From the depths of despair around him, he wrote in 1930 of the Economic Possibilities of our Grandchildren. At a time of duress and suffering, he envisioned the end of poverty in Great Britain and other industrial countries in his grandchildren's day, toward the end of the twentieth century .... Keynes got it just right, of course: extreme poverty no longer exists in today's rich countries, and is disappearing in most of the world's middle-income countries. Today we can invoke the same logic to declare that extreme poverty can be ended not in the time of our grandchildren, but in our time. The wealth of the rich world, the power of today's vast storehouses of knowledge, and he declining fraction of the world that needs help to escape from poverty all make the end of poverty a realistic possibility by the year 2025 .

Arguably, analysis of Sachs' (2005) and Sachs et al.'s (2005) work is not complete without insight into their values, which motivate the big push agenda, and its underlying discourses. An understanding of the vision which underlies the big push agenda offers important insights into the normative dimension of the big push agenda. Having offered an overview of certain seminal contributions to the big push advocacy literature, an analysis of geography as a 'deep determinant' constraint to development is now considered.

\section{Geography}

At the heart of arguments for large-scale aid, or big push interventions, is a consideration of geographical disadvantage. Only aid contributions on the same scale as the effects of geographic disadvantage (or on a sufficient 'threshold' scale) can provide the prerequisite conditions for growth or take-off (Sachs 2005; Sachs et al. 2005). In order to understand this argument, it is necessary to first understand the specifics of how geographic effects can constrain growth, and an overview of these is provided as follows.

\section{Geographic modelling}

An introduction to arguments offered by Gallup, Sachs and Mellinger (1999) is now offered. Of central importance to the arguments offered in support of the centrality of geography as the primary force accounting for differences in development is the notion of Gallup et al. (1999) offered a Harrod-Domar model with transport costs included. This model includes total factor productivity $(A)$, which is taken to differ (1) geographically, for reasons related to temperate and tropical agriculture and endemic health conditions, (2) in terms of transport costs, related to distances and physical access to trade in terms of river navigability or distance from the coast, (3) according to national savings rates and (4) according to economic policies of governments. Their logic is summarised as follows, starting with the aggregate production function below:
The capital stock $(K)$ is taken to change according to the following equation, in which $I$ is the investment and $\delta$ is the rate of investment.

$$
d K / d t=I-\delta K
$$

Assuming constant population which is normalised to $1, Q$ would then reflect output as well as input per capita. If the national savings rate is fixed at $s$, the price of investment goods relative to final output is $P_{\mathrm{I}}$. Therefore:

$$
s Q=P_{\mathrm{I}} I
$$

The economy's growth rate is therefore:

$\gamma=1 / Q * d Q / d t=1 / K * d K / d t=s A / P_{\mathrm{I}}-\delta$

According to this equation derived by Gallup et al. (1999), economic growth is a function of the savings rate $(s)$ and level of productivity $(A)$, but negatively related to the relative price of capital goods $P_{\mathrm{I}}$ as well as the rate of depreciation $(\delta)$. The relative prices of capital goods are, however, to some extent a function of transport costs because a large proportion of investment goods have to be imported. Indeed, in developing countries, almost all are imported (Gallup et al. 1999).

To further analyse effects related to transport costs, Gallup et al. (1999) developed another model. In this model, each country is considered to produce a distinct final good with investment, a composite of final goods produced in different countries, under the assumption that gains from trade exist and that transport costs and other barriers to trade reduce growth. According to this model, total investment depends on investment expenditure on domestic goods $\left(I^{d}\right)$ as well as imported goods $\left(I^{m}\right)$ :

$$
I=I\left(I^{d}, I^{m}\right)
$$

To illustrate this further, Gallup et al. (1999) considered I, a Cobb-Douglas function of underlying domestic and foreign investment goods. They then developed the model further, reaching the conclusion that the growth rate is inversely related to the cost of transport. The implication of this is that transport costs therefore reduce growth through the higher costs associated with imported capital goods. This implication echoes literature suggesting that rates of growth are decreasing functions of the relative costs of investment goods. Gallup et al. (1999) extended their analysis further to include the influence of transport costs on intermediate goods (e.g. fabrics or electronic components). Intermediate goods can also be a requirement for final production which uses lowcost assembly for re-export. Therefore, on the basis of this further analysis, even relatively small transport costs are found to potentially have strong effects on output and growth when intermediate inputs are a large component of final demand. Multistage processing of output can, therefore, use specialised inputs produced in different regions, and only coastal or coastal-linked areas can compete. An implication of these results is that the channel to development offered by 
assembly manufacturing may be inaccessible to hinterland regions. Geography is, therefore, a dominant constraint to their development.

The AK model, however, does not predict convergence (no diminishing returns to investment in production), so capital depending is not expected to be associated with slowing growth. Accordingly, countries with advantages in savings rates, efficiency, transport costs or depreciation rates are predicted to potentially attain permanently higher growth rates and divergence can occur (Gallup et al. 1999). An important implication of this model, therefore, relates to temporal effects. If transport costs allow early historical advantage, then even if growth rates converged, this initial advantage is expected to persist in terms of relative income levels. If increasing-returns-to-scale models are applied to the analysis, positive growth divergence could result as a result of their dependence on levels of capital (which are high because of historical transport advantage) (Gallup et al. 1999). A large-scale influx of aid (as per Sachs et al. 2004) would be needed in this instance if geographic equity were to be achieved.

The extent to which geography might shape institutions is also an important issue, and this is now considered in terms of Gallup et al.'s (1999) analysis.

\section{Geography and economic policy choice}

Gallup et al. (1999) stressed that geography not only influences growth through the channels of productivity and transport costs but also through its influence on policy choices. Countries closer to markets, for example, may tend to choose more open trade policies. Taxation levied might pit revenue collection against the policy environment, where governments maximise utility and can choose higher tax revenue at the cost of future growth (Gallup et al. 1999). With low growth because of geographical influence and growth unresponsive to policy, revenue-maximising governments may tend to impose higher rates of taxation. Such higher taxation can be associated with protectionist policies. On the contrary, with more productive economies and under conditions where growth is more responsive to policies, governments may be incentivised to tax less. These dynamics can amplify differences between these two types of countries (Gallup et al. 1999). A methodological identification problem may also arise from tested associations between taxation and growth. A negative association can be interpreted as the importance of policy for growth, but according to the logic of amplification of differences it could be that growth has an important influence on policy (Gallup et al. 1999).

Gallup et al. (1999) tested convergence versus divergence effects using cross-country growth equations incorporating catching-up effects, concluding that (1) both geography and policy matter, (2) tropics are not conducive to growth (primarily related to malaria as a variable), which might also proxy tropical maladies in general that are geographically associated with malaria, (3) coastal regions lower transport costs and create agglomeration economies, (4) high population growth seems to hinder growth inland but supports growth in coastal regions and (5) distance from core markets is not an important driver of economic growth. Aid programmes which improve transport infrastructure for landlocked countries to access ports also require cooperation between different countries, which are typically difficult to coordinate and neglected by country-based donor projects.

According to Gallup et al. (1999:212), 'the policy implications of these findings, if the findings are true, are staggering' and aid programmes 'should be rethought'. They argued that research agendas need to be reshaped in the light of the importance of geographical variables, as neglecting geography may overstate the role of policy variables in economic growth and neglect deeper constraints associated with geography.

Having considered different sides of the historical geography versus institutions debate in relation to sub-Saharan countries, certain perspectives relating to the effectiveness of aid are now considered, prior to reporting on the progress of the MDG aid process in 2015.

\section{Effectiveness of aid flows}

The tension in the literature between advocates of geographic and institutional effects is to some extent reflected, respectively, in tensions between advocates for big push, or pro-aid interventions and those who are not.

Anderson et al. (2012) provided a critique of the contemporary aid system, suggesting aid reform to change the system from one based on externally driven delivery to a more collaborative system. This critique, based on insights from those receiving aid, relates to processes and systems of the international aid system which undermines its effectiveness and the way assistance can become entrenched as an increasingly complicated system of reciprocal dependence. 'Smarter' and more effective aid delivery is therefore needed, as much is wasted through misguided programmes or lack of provider engagement. To achieve its intent, fundamental reform in its processes are required if aid is to support positive economic, social and political change, which it can do if applied effectively (Anderson et al. 2012). Edwards and Hulme (1998) suggested the possibility that dependence on official funding can compromise non-governmental organisations in key areas. This can distort accountability and weakening legitimacy. The arguments made in this article are made with full acknowledgement of such critiques of the global aid delivery system and the need to address these issues. However, such problems are not considered to lessen the needs of those most vulnerable and should arguably not stand in the way of increased assistance where warranted.

If modern economic growth in geographically constrained Africa will only occur when geographical constraints are overcome, then this is a process dependent on external funding, using the MDGs as initial targets (Sachs et al. 2005). This argument is to some extent supported by other 
perspectives that geographically based increasing returns justify large-scale interventions to finance preconditions for growth (O'Connell 2004). In fact, in terms of the effectiveness of aid, little evidence supports 'new Washington consensus' that aid cannot function with weak institutions and that conditionality has not worked (Kremer 2004). Aid to states with bad governments can also be effective in reaching those most in need, as government spending may ignore social ends. Private and non-profit organisations can be strengthened together with alternative power bases, although this does raise incentive issues (Kremer 2004). The institutionist argument is, therefore, not incommensurate with the big push argument. This is also recognised by Sachs et al. (2004).

Aid can be effective on account of its inherent characteristics. MDGs have intrinsic appeal as merit goods and are well defined and targeted at poverty reduction and human development, providing a useful framework for overcoming conflicts of interest and providing a uniting logic in objectives (O'Connell 2004). Further, aid can be better than commodity rents, as donors have an interest in what is being financed. Aid typically does not lead to armed conflict in the same way as natural resource abundance can (O'Connell 2004). Poverty trap models assume microeconomic non-convexities (such as lumpy capital investments), but little evidence suggests that these exist at the macroeconomic level. If transport and communications infrastructure is needed, this can be provided in a single location and expanded outward, limiting macroeconomic non-convexities (Kremer 2004). This supports the Sachs et al. (2004) argument from an infrastructure big push perspective.

The effectiveness of aid can also be increased by considering what it is channelled to. Scaling up donor aid in scienceintensive regional public goods, such as basic research in health and agriculture, is useful. Precedent exists, such as eradicating polio and developing high-yield seed types in the Asian Green Revolution (O'Connell 2004). Aid needs to be integrated with country priorities and toward ends which offer sensible paybacks. Developing agriculture might be problematic if low transport costs make it possible only for countries with comparative advantage to sustain agriculture (Glaeser 2004). Aid in science-intensive regional public goods, however, is relatively more robust to time horizon constraints but large-scale aid, however, is not ( $\mathrm{O}^{\prime}$ Connell 2004). At the microeconomic level, the case for aid should be based on serious human needs. Even small amounts of aid can have an important impact on certain local problems, such as access to clean water, vaccinations and transport to support trade (Kremer 2004). Interventions should also be targeted which 'work'. The workability of interventions should be researched. However, in contrast to those opposing increases in aid who argue capacity constraints are a dominant impediment, it is possible that expectations or requirements for 'sustainability' of aid create this problem. Certain issues, such as vaccination and funding teachers' salaries, need to be acknowledged as long-horizon issues in the first place (Kremer 2004). Overall, big push or poverty trap evidence is empirically just as consistent as conventional growth models which prioritise government quality and policies as determinants of steady-state income, according to Kremer (2004). Arguably, if aid was increased on normative grounds, it could mitigate the global birth lottery effect, and one 'very big push', if successful, could subsequently increase the societal and economic returns to investments.

Aid management practices are also improving. Although outcomes-based assessments have improved aid delivery, MDG services remain transactions-intensive and discretionary. If overly discretionary, important actions can be unobservable. This 'unobservability' is perhaps reflected in problematic empirical linkages between spending on education and health and outcomes. Intrinsic incentive problems therefore prevail, unlike the effects of macroeconomic policy (O'Connell 2004). According to the institutionalist school, aid can be ineffective because of poor governance. If rule of law and institutions are indeed an insurmountable obstacle to investment and infrastructure development, and if these effects were robust to aid, other measures might be needed, such as UN trusteeship backed with forces to support minimal law and order so aid can be used properly (Cooper 2004). There also seem to be other options, according to this literature, which contest the more cynical aid effectiveness discourses associated with what Sachs et al. (2004) termed the 'standard diagnosis' or 'standard view'.

\section{The 'standard view' or 'standard diagnosis'}

The 'standard view' is taken to incorporate perspectives critical of the big push logic. According to Cooper (2004), many successful countries (e.g. Switzerland) are landlocked with low natural resources, and Africa is not in a subsistencelevel poverty trap as it has been growing. Further, aid is wasted because of lack of elementary functions of law and order needed to deliver it effectively (Cooper 2005), which is not adequately considered by big push model advocates (Kremer 2004). According to O'Connell (2004), aid to Africa has been flowing for a long time, with much misdirected. He questioned what is really new about the big push narrative, and whether such a bold approach is not simplistic as it ignores uncertainties and other problems of delivery. Further, O'Connell (2004) argued big push ideas typically lack a sufficient consideration of 'what next?' We need to admit that we do not know much about how to enable growth in Africa, or when it will happen, according to Kremer (2004). Kremer suggested a greater body of evidence that indicates government quality is more important for growth than the evidence which supports the poverty trap view. He argued that big push advocacy effectively reduces to vintage capital fundamentalism, which has been rejected in the literature as a viable interpretation of Africa's development path. Poverty trap models predict large negative shocks cause stagnation. In contrast, however, economies experiencing these have subsequently been the fastest growing in Africa (e.g. Uganda and Mozambique), although aid has played a major role (Kremer 2004). Another challenge in research is that traditional measures of governance do not pick up absence of 
government sufficiently (Kremer 2004). What unites these perspectives is their challenge to the effectiveness of aid argument of poverty trap theory. These critiques are answered in the same way as they have been above, in different forms that institutional quality does not make aid effectiveness impossible - it merely constrains it. And it might be that geographical constraints are at the heart of governance challenges too.

Governance does not need to be considered relative to income as this is not the critical indicator for successful aid. Rather the question is whether governance is good enough in absolute terms to avoid sharply diminishing returns or institutional deterioration under increasing scale of public service provision (O'Connell 2004). An excess focus on deep determinants might preclude a proper focus on absorptive capacity. If financial resources were the key constraint to Africa's development, persistent commodity booms would be expected to provide trap exit. Instead, commodity rents may have been the centre of distributional contests undermining policy and institutional performance (O'Connell 2004). Big push narratives also typically dismiss Dutch disease effects. Furthermore, large and continual aid inflows can boost domestic spending on non-traded goods, hurting competitiveness, as real exchange rates cannot be fixed for more than a short interval. Big push logics also assume sequencing whereby export diversification is secondary, but empirical evidence suggests the importance of trade for development (O'Connell 2004). Massive aid transfers could hurt Africa if real appreciation of currencies result (Gordon 2004). According to Gordon, big push notions assume perfect delivery but advocate scaling up financing and the mandate of weak institutions. This can potentially exacerbate existing weaknesses and potentially enable dependency traps, as donor activities drive out institutional learning-by-doing. Consequently, high-aid, low-institutional-capacity equilibria can develop, even in crises following four decades of relatively high aid (O'Connell 2004). Briefly, big push logics require improving effectiveness of aid, but deep associations between poverty and poor institutional capability require consideration of absorptive capacity, typically neglected in big push literature ( $\mathrm{O}^{\prime}$ Connell 2004). It is argued that most of these issues can be incorporated into Sachs et al.'s (2004) model and that its central thesis stands that if structural constraints (such as geographical inequity) can be removed via big push aid interventions, preconditions to improved growth can result.

\section{Donor aid and MDGs}

Given Sachs (2005) and Sachs et al. (2004) explicitly link advocacy of the big push approach to the MDG process, a review of criticisms of the donor and MDG process is also considered relevant. According to Kremer (2004), tying aid to MDGs can distort how funds are spent. Donors typically do not provide sufficient resources, and poor countries have other needs as well. MDG processes can lack local participatory input. This is particularly important as donor funding is typically a component of bilateral foreign policy.
Political changes can occur, and aid cannot have longer horizons than weak institutional uncertainties (O'Connell 2004). Resistance to donor efforts can also hinder aid effectiveness, as countries have priorities according to their needs, and large-scale big push approaches might conflict with these priorities (O'Connell 2004).

Poverty trap models suggest high returns for private investments by locals, but this is less evident in empirical evidence. Certain African economies have decreased in GNP per capita (Kremer 2004). MDGs do not consider benefits after deadlines have expired, and national development plans built around MDGs will face problems if external funding does not materialise. Important priorities like vaccinations can in time be crowded out by other objectives (Kremer 2004). According to Kremer (2004), it is not known whether fundraising benefits of MDGs will, on balance, be larger than potential distortions caused to development planning. He argued that a more modest and microeconomically sound approach to aid might be better than an approach based on big push logics.

In the above sections, discussions provided the basis for an evaluation of arguments around the tension between geographic versus institutional perspectives and the implications for aid to sub-Saharan countries. Evidence offered by the 2015 review of the MDGs is considered in Section 'Hindsight: 2015 millennium development goals', in order to provide a perspective of the extent to which the big push approach has in fact delivered on its promises, given 2015 as the MDG target year. Prior to this, however, a further (and hitherto unconsidered) contesting argument is discussed, which offers another perspective of what might constrain sub-Saharan economic development, based on the notion that African economies face poverty traps more specifically associated with sectoral-level effects.

\section{A contesting argument}

In the sections above, debates between geographic-centric and institution-centric perspectives were considered in relation to the pro-aid debates associated with the former and anti-aid stance typically associated with the latter. At this nexus, however, a further argument is introduced which contests the geographic and institutional literatures in terms of its explanation of the dominant cause of underdevelopment. This contesting argument, however, is nonetheless also taken to support the need for dramatic interventions and increased development assistance for poor countries, as it argues African economies face a lack of development because of deindustrialisation (Tregenna 2009, 2014). This condition is termed here a 'deindustrialisation' trap.

Palma (2008) differentiated between three bodies of theory differentiated by the way they model growth (and therefore development). This differentiation is framed in terms of their focus on activities (such as research and development [R\&D] and education) versus sectors (e.g. the manufacturing sector). The first category, for Palma, includes Solow-type models 
as well as endogenous growth theory that focus on the production function at the expense of R\&D or human capital activities. This category is associated with an 'activityindifferent' and 'sector-indifferent' approach to growth. The second category relates to what Palma described as activityspecific theory such as that of Romer and neo-Schumpeterian theorists who focus on activities such as R\&D but who are sector-indifferent in their theory development. In contrast, the third category relates to theory which incorporates both activity and sectoral effects, such as Post-Keynesian, Schumpeterian and Structuralist theory building on the work of Kaldor (1970). This work focuses on patterns and dynamics of growth driven by manufacturing because of technological change, externalities, synergies, balance-of-payment effects and learning-by-doing. According to this perspective, development catch-up is essentially a function of the size, strength and depth of manufacturing sectors. However, structural adjustment programmes and liberalisation reforms in African economies have typically not paid sufficient attention to erosion of important parts of the industrial base necessary for future growth (Noorbakhsh \& Paloni 1999). Given that historically no country has ever attained developed country status without it being on the back of industrialisation, and given the current global trend towards deindustrialisation (Tregenna 2014), it is argued here that without dramatic increases in development aid, sub-Saharan economies face conditions inimical to catch-up or economic convergence with developed economies.

A visionary approach to these problems on the scale of Sachs et al.'s (2004) big push logic is perhaps needed, with this justified on account of the birth lottery rationale, drawing from the principles of social justice. The feasibility of this suggestion, however, rests on the assumption of effectiveness of aid. The impact of aid can perhaps be reflected in the extent to which developmental goals have been met because of aid investments. Attainment of the MDGs is now considered to this end.

\section{Hindsight: 2015 millennium development goals}

Kremer's (2004:222) perspective summarised another implication of what Sachs et al. (2005) might consider the standard critique of the big push approach, namely that:

[i]nstead of setting macroeconomic goals, such as escaping from a poverty trap or achieving the MDGs, and then planning aid around them, it would be better to make decisions based on microeconomic evidence on the impact of particular programs and policies.

Arguably, these notions are not mutually exclusive; it goes without saying, perhaps, that implementation should not exclude microeconomic considerations. It is argued in this article, however, that only a large-scale aid intervention approach, or rationale, can capture the vision and provide a normative logic for large-scale intervention, as offered by
Sachs et al. (2005) which draws on the grand vision of Keynes. To some extent, the relative success of the big push agenda, with its geographic-centric perspective, as conceptualised by Sachs et al. (2005), is perhaps reflected in an assessment of the achievements of the MDGs. These are considered as follows.

In terms of the first MDG goal, to eradicate extreme poverty and hunger, whereas in 1990 almost half the developing world population lived on less than $\$ 1.25$ per day, this proportion has dropped to $14 \%$ in 2015 . The proportion of those living in extreme poverty has fallen from 1.9 billion in 1990 to 836 million, with most progress occurring since 2000 (United Nations 2015). According to the second goal, to achieve universal primary education, the primary net enrolment rate climbed from $83 \%$ in 2000 to $91 \%$ in 2015 . A $20 \%$ point increase in net enrolments was realised from 2000 to 2015 for sub-Saharan Africa. Achievements against the third goal, to promote gender equality and empower woman, include an increase in female parliamentary representation (a doubling of average proportion) to $90 \%$ of the 174 countries with data. Over the period 2000-2015, the target of eliminating gender disparity in primary, secondary and tertiary education has been achieved in developing regions on the whole. Against the fourth goal, to reduce child mortality, the global under-five mortality rate has declined by more than half, from 90 to 43 deaths per 1000 live births over the years 1990-2015. Despite population growth, in sub-Saharan Africa, the annual rate of reduction of under-five mortality rose fivefold for the period 20052013 over and above the period 1990-1995. A 67\% decline in globally reported measles cases has occurred across the years 2000-2013, as measles vaccine coverage has risen from $73 \%$ in 2000 to $84 \%$ in 2013 (United Nations 2015). In terms of the fifth goal, to improve maternal health, since 1990 the maternal mortality ratio has dropped by $45 \%$ worldwide, and by $49 \%$ in sub-Saharan Africa over the years 1990 to 2013. The sixth goal, to combat HIV/AIDS, malaria and other diseases, has also seen dramatic advances, such as a fall in new HIV infections by about $40 \%$ between 2000 and 2013. Further, 13.6 million were receiving antiretroviral treatment globally by 2014, up from 800000 in 2003 . Consequently, an estimated 7.6 million deaths have been averted between 1995 and 2013. These successes are also reflected in a drop in the global malaria incidence rate by $37 \%$ and in the malaria mortality rate by $58 \%$ for the period 2000-2015. Similarly, a 45\% fall in the tuberculosis mortality rate and a $41 \%$ fall in the prevalence rate has occurred over the period 1990-2013. These advances are particularly important for Southern Africa which as a region faces the highest HIV disease burden in the world. Progress against the seventh goal, to ensure environmental sustainability, is evident in the elimination of ozone-depleting substances since 1990. At this rate, the ozone layer is expected to regain its coverage by about 2050. An increase from $76 \%$ to $91 \%$ of the global population now has access to an improved drinking water source. The proportion of urban populations living in slums in developing regions has reduced from about $39.4 \%$ to $29.7 \%$ across the years $2000-2014$. 
Finally, dramatic progress has also been made against the eighth goal, to develop a global partnership for development, as contributions by Denmark, Luxembourg, Norway, Sweden and the United Kingdom have exceeded the UN target of $0.7 \%$ of gross national income. Further, by 2014, $79 \%$ of imports from developing countries were duty free. This is in contrast to $65 \%$ in 2000 . Furthermore, the ratio of external debt service to export revenue in developing countries dropped from $12 \%$ in 2000 to $3 \%$ in 2013. By 2015, $95 \%$ of populations across the world were covered by mobile-cellular signals. This increase has been matched by an increase in Internet penetration from $6 \%$ to $43 \%$ over the years 2000-2015. A total of 3.2 billion people are now connected to global networks of content and applications.

The big push advocates sought to dramatically increase donor aid support to achieve MDGs. To what extent did aid increase in response to these goals? ODA from developed countries increased $66 \%$ (in real terms) between 2000 and 2014 to a high of $\$ 135.2$ billion (United Nations 2015). The general successes of the MDG programme is summarised by Moon (2015:3) as follows:

The global mobilization behind the Millenium Development Goals has produced the most successful anti-poverty movement in history.... The MDGs helped to lift more than one billion people out of extreme poverty ... [and] generated new and innovative partnerships, galvanized public opinion and showed the immense value of setting ambitious goals. By putting people and their immediate needs at the forefront, the MDGs reshaped decision-making in developed and developing countries alike.

However, despite dramatic successes, poorest populations most vulnerable to poverty and inequality are still being left behind, as progress has been uneven. Sex, age, disability, ethnicity and geographic locations are persistent dimensions of disadvantage which in addition to climate change and global conflict present serious ongoing challenges (United Nations 2015).

Despite these ongoing challenges, Moon (2015:3) stressed '[e] xperiences and evidence from the efforts to achieve the MDGs demonstrate that we know what to do' and further progress will require 'an unswerving political will, and collective, long-term effort'. The emerging post-2015 development agenda includes the new set of sustainable development goals, which strive to 'put all countries, together, firmly on track towards a more prosperous, sustainable and equitable world' according to Moon (2015:3), who concluded that:

[r]eflecting on the MDGs and looking ahead to the next fifteen years, there is no question that we can deliver on our shared responsibility to put an end to poverty, leave no one behind and create a world of dignity for all.

Perhaps a 'big push', with a much bigger aid investment than the MDG process, can reach a tipping point for poverty eradication. Given certain successes of the MDG project, it is argued that a normative rationale exists for radically increased aid, based on the principle of mitigation of the global birth lottery effect. Perhaps, it is time to take recourse to certain normative approaches. In the light of human suffering and the plight of millions, perhaps it is a moral imperative to do so.

\section{Conclusions}

The objective of this article was to interrogate certain arguments based on an analysis of contestation between different literatures seeking to prioritise either geography or institutions at the expense of the other. On the one hand, an institutionalist approach typically predicts that aid investments will be less effective in development and the primary constraint to development is poor governance. On the other hand, an approach grounded in geographical inequity suggests that geographic conditions pose a structural constraint to development. According to this approach, geographic conditions can shape institutional quality as well as trade development, and only very large external aid-based interventions might balance out these geographic inequalities. Such interventions might be able to enable the development of basic or minimum threshold levels of infrastructure required for upliftment, termed 'take-off'. It was argued that only a macroeconomic approach coupled with a grand vision on the scale of Keynes's might be able to make inroads into such serious conditions. The need for such an approach was considered particularly salient for most Southern African economies, which face not only developmental challenges shared with other sub-Saharan countries but in addition face the highest HIV disease burden in the world. It is concluded here that the work of Sachs et al. (2004), together with the global consensus and collaborations of the MDG process and its very large aid contributions, has established a new standard of human-centred economic analysis and practice. This new standard, reflected in the MDG accomplishments, arguably shows that pro-poor normative 'big vision' approaches in the tradition of Keynes can be useful in a world still dominated by extreme poverty, deprivation and desperation.

\section{Acknowledgements Competing interest}

The author declares that he has no financial or personal relationship(s) which may have inappropriately influenced him in writing this article.

\section{References}

Acemoglu, D., Gallego, F.A. \& Robinson, J.A., 2014, 'Institutions, human capital and development', Annual Reviews of Economics 6, 875-912. http://dx.doi.org/ 10.1146/annurev-economics-080213-041119

Acemoglu, D., Johnson, S. \& Robinson, J.A., 2001, 'The colonial origins of comparative development: An empirical investigation', American Economic Review 91, 1369-1401. http://dx.doi.org/10.1257/aer.91.5.1369

Anderson, M.B., Brown, D. \& Jean, I., 2012, Time to listen. Hearing people on the receiving end of international aid, CDA Collaborative Learning Projects, Cambridge, MA, viewed 27 October 2016, from http://cdacollaborative.org/search-publications/ ?fwp_search=time+to+listen

Bezuidenhout, H., 2009, 'A regional perspective on aid and FDI in Southern Africa', International Advances in Economic Research 15(3), 310-321. http://dx.doi. org/10.1007/s11294-009-9232-9 
Cooper, R., 2004, In J.D. Sachs, J.W. McArthur, G. Schmidt-Traub, M. Kruk, C. Bahadur, M. Faye \& G. McCord, 'Ending Africa's Poverty Trap', Brookings Papers on Economic Activity $1,117-240$

De Wall, A. \& Whiteside, A., 2003, 'New variant famine: AIDS and food crisis in Southern Africa', The Lancet 362(9391), 1234-1237. http://dx.doi.org/10.1016/ S0140-6736(03)14548-5

Easterley, W., 2006, 'Reliving the 1950s: The big push, poverty traps, and takeoffs in economic development', Journal of Economic Growth 11, 289-318. http://dx.doi. org/10.1007/s10887-006-9006-7

Edwards, M. \& Hulme, D., 1998, 'Too close for comfort? The impact of official aid on nongovernmental organisations', Current Issues in Comparative Education 1(1), 1-21.

Fowler, A., 1991, 'The role of NGOs in changing state-society relations: Perspectives from Eastern and Southern Africa', Development Policy Review 9(1), 53-84. http:// dx.doi.org/10.1111/j.1467-7679.1991.tb00175.x

Gallup, J.L., Sachs, J.D. \& Mellinger, A.D., 1999, ‘Geography and economic development', International Regional Science Review 22(2), 179-232. http://dx. doi.org/10.1177/016001799761012334

Glaeser, E., 2004, In J.D. Sachs, J.W. McArthur, G. Schmidt-Traub, M. Kruk, C. Bahadur M. Faye \& G. McCord, 'Ending Africa's poverty trap', Brookings Papers on Economic Activity 1, 117-240.

Gordon, R., 2004, In J.D. Sachs, J.W. McArthur, G. Schmidt-Traub, M. Kruk, C. Bahadur, M. Faye \& G. McCord, 'Ending Africa's poverty trap', Brookings Papers on Economic Activity 1, 117-240.

Kaldor, N., 1970, 'The case for regional policies', Scottish Journal of Political Economy 17(3), 337-348.

Kremer, M., 2004, In J.D. Sachs, J.W. McArthur, G. Schmidt-Traub, M. Kruk, C. Bahadur, M. Faye \& G. McCord, 'Ending Africa's poverty trap', Brookings Papers on Economic Activity 1, 117-240.

Loots, E., 2006, 'Aid and development in Africa: The debate the challenges and the way forward', South African Journal of Economics 74(3), 363-381.

Luiz, J.M., 2016, 'The political economy of middle-income traps: Is South African in a long-run growth trap? The path to "Bounded Populism"', South African Journal of Economics 84(1), 3-19. http://dx.doi.org/10.1111/saje.12117

Moon, B., 2015, Foreword, The millennium development goals report 2015, United Nations, viewed 13 October 2015, from http://www.un.org/millenniumgoals/2015 MDG_Report/pdf/MDG\%202015\%20rev\%20(July\%201).pdf

Nelson, R., 1956, 'A theory of the low-level equilibrium trap in under-developed economies', American Economic Review 46(5), 894-908.

Noorbakhsh, F. \& Paloni, A., 1999, 'Structural adjustment programs and industry in sub-Saharan Africa: Restructuring of de-industrialisation?', The Journal of Developing Areas 33(4), 549-580.
O'Connell, S.A., 2004, In J.D. Sachs, J.W. McArthur, G. Schmidt-Traub, M. Kruk, C. Bahadur, M. Faye \& G. McCord, 'Ending Africa's poverty trap', Brookings Papers on Economic Activity 1, 117-240.

Palma, J.G., 2008, 'Deindustrialisation, premature deindustrialisation, and the Dutch disease', in L.E. Blume \& S.N. Durlauf (eds.), The new Palgrave: A dictionary of economics, 2nd edn., pp. 401-410, Palgrave Macmillan, Basingstoke.

Parente, S.L., 2001, 'The failure of endogenous growth', Knowledge, Technology \& Policy 13(4), 49-58. http://dx.doi.org/10.1007/BF02693989

Rodrik, D., Subramanian, A. \& Trebbi, F., 2004, 'Institutions rule: The primacy of institutions over geography and integration in economic development', Journal of Economic Growth 9(2), 131-165. http://dx.doi.org/10.1023/B:JOEG.0000031425. 72248.85

Romer, P.M., 1994, 'The origins of endogenous growth', Journal of Economic Perspectives 8(1), 3-22. http://dx.doi.org/10.1257/jep.8.1.3

Rosenstein-Rodan, P.N., 1943, 'Problems of industrialisation of Eastern and SouthEastern Europe', The Economic Journal 53(210/211), 202-211. http://dx.doi.org/ 10.2307/2226317

Rosenstein-Rodan, P.N., 1961, 'International aid for underdeveloped countries', The Review of Economics and Statistics 43(2), 107-138. http://dx.doi.org/10.2307/ 1928662

Rostow, W.W., 1960, The stages of economic growth: A non-communist manifesto, Cambridge University Press, Cambridge.

Sachs, J.D., 2005, The end of poverty: Economic possibilities for our time, The Penguin Press, New York.

Sachs, J.D., McArthur, J.W., Schmidt-Traub, G., Kruk, M., Bahadur, C., Faye, M. et al., 2004, 'Ending Africa's poverty trap', Brookings Papers on Economic Activity 35(1), 117-240. http://dx.doi.org/10.1353/eca.2004.0018

Solow, R.M., 1956, 'A contribution to the theory of economic growth', Quarterly Journal of Economics 70(1), 65-94. http://dx.doi.org/10.2307/1884513

Tregenna, F., 2009, 'Characterising deindustrialisation: An analysis of changes in manufacturing employment and output internationally', Cambridge Journal of Economics 33(3), 433-466. http://dx.doi.org/10.1093/cje/ben032

Tregenna, F., 2014, 'A new theoretical analysis of deindustrialisation', Cambridge Journal of Economics 38(6), 1373-1390. http://dx.doi.org/10.1093/cje/ bet029

United Nations, 2015, The millenium development goals report 2015, viewed 13 October 2015, from http://www.un.org/millenniumgoals/2015_MDG_Report/ pdf/MDG\%202015\%20rev\%20(July\%201).pdf

Zerbe, N., 2004, 'Feeding the famine? American food aid and the GMO debate in Southern Africa', Food Policy 29(6), 593-606. http://dx.doi.org/10.1016/j. foodpol.2004.09.002 